\title{
Genetic therapies for neurological disorders
}

\author{
Laura FitzPatrick ${ }^{1}$. $\cdot$ Adrian Bird ${ }^{1}$
}

Received: 30 September 2021 / Accepted: 3 November 2021 / Published online: 22 November 2021

(c) The Author(s) 2021

\begin{abstract}
In recent years, it has become increasingly apparent that many neurological disorders are underpinned by a genetic aetiology. This has resulted in considerable efforts to develop therapeutic strategies which can treat the disease-causing mutation, either by supplying a functional copy of the mutated gene or editing the genomic sequence. In this review, we will discuss the main genetic strategies which are currently being explored for the treatment of monogenic neurological disorders, as well as some of the challenges they face. In addition, we will address some of the ethical difficulties which may arise.
\end{abstract}

\section{Introduction}

Recent advances in DNA sequencing technology have led to an explosion of knowledge about the genetics of human disease, and the realisation that many more disorders are genetic in origin than previously thought. For example, large-scale exome-sequencing projects, such as the Deciphering Developmental Disorders study, have identified novel pathogenic de novo mutations in patients with undiagnosed neurodevelopmental conditions (Fitzgerald et al. 2015; McRae et al. 2017). The new knowledge has led to a surge of interest in the potential for therapies which address the genetic root cause of these disorders, rather than attempting to treat secondary consequences. These approaches include conventional gene therapy (also referred to as "gene transfer") which aims to restore function of the mutated gene by introducing a functional copy into cells (Friedmann and Roblin 1972). In addition, advances in our ability to re-write DNA sequences via genome editing, particularly "clustered regularly interspaced short palindromic repeats" (CRISPR) technology, have sparked interest in their use for the treatment of a variety of disorders. All of these approaches are particularly suited to monogenic conditions which, in theory, can be cured by correction of the disease-causing mutation.

Laura FitzPatrick

1.a.fitzpatrick@sms.ed.ac.uk

Adrian Bird

a.bird@ed.ac.uk

1 Wellcome Centre for Cell Biology, University of Edinburgh, The Michael Swann Building, Max Born Crescent, Edinburgh EH9 3BF, UK
In this review, we illustrate the growing therapeutic potential of these developing technologies. We also consider the technical challenges still to be overcome, as well as some ethical issues posed by genetic interventions in the brain.

Like many medical innovations, genetic therapies rely on basic knowledge acquired in model organisms. Importantly, there needs to be evidence that symptoms have the potential to be alleviated or even cured. A disorder which highlights the value of pre-clinical research is Rett syndrome (RTT), a severe neurological disorder caused by mutations in the X-linked gene MECP2 (Amir et al. 1999). Mouse models recapitulate many features of the human condition (Chen et al. 2001; Guy et al. 2001), supporting the conclusion that the function of the MeCP2 protein is the same in mice as in humans. Importantly, the majority of symptoms can be reversed in adult Mecp2-null mice by restoring expression of the wild-type protein (Guy et al. 2007; Robinson et al. 2012). This suggests that RTT is curable well after the onset of symptoms. Phenotypic reversibility of a few other monogenic neurological conditions has been tested using mouse models, with variable results. For example, restoration of Ube $3 a$ expression in young mice leads to reversal of many adverse phenotypes in a model of Angelman syndrome, but not all autism-related phenotypes are reversed when the gene is activated in older animals (Silva-Santos et al. 2015). These findings point to an early window for therapeutic intervention. In all neurodevelopmental disorders of this type, basic understanding of the function of the mutated gene and its time of action during life is an important pre-requisite for intervention. 


\section{What genetic interventions are under development?}

\section{Gene transfer}

The technically most straightforward approach to genetic therapy involves introduction of wild-type copies of the affected gene into the nucleus of appropriate cells in the brain (Friedmann and Roblin 1972). To successfully achieve this, a suitable delivery vehicle which can efficiently bring genetic material to the target cells is required. At present, adeno-associated viral (AAV) vectors are the preferred delivery vehicle for the central nervous system (CNS) due to their relatively favourable safety profile and the potential of certain serotypes (such as AAV9) to cross the blood-brain barrier, infect post-mitotic neurons and provide widespread and sustained transgene expression throughout the brain (reviewed in Hudry and Vandenberghe 2019). The advantages and disadvantages of AAV vectors will be considered in more detail later.

The success of gene transfer has been demonstrated for several genetic disorders, and AAV-based therapies have been clinically approved for use in humans, including Glybera and Luxturna for the treatment of lipoprotein lipase deficiency and RPE65 mutation-associated inherited retinal dystrophy, respectively (reviewed in Ginn et al. 2018). More recently, in 2019, Zolgensma was approved for the treatment of spinal muscular atrophy (SMA). Introduction of a functional SMN1 (survival motor neuron 1) gene into motor neuron cells effectively prevents fatal loss of muscle function in children with SMA (Mendell et al. 2017).

\section{Genome editing using programmable nucleases}

An ideal genetic therapy would correct the mutated gene by "re-writing" its DNA sequence to rectify the mistake. Not only does this address the root cause of the problem, but its effect would be permanent. Initial approaches have involved fusing DNA binding domains that can target a specific genomic location with high accuracy, to nucleases, which generate double-stranded breaks (DSBs) in the DNA (reviewed in Cox et al. 2015). These include the CRISPR/ Cas9 system, which is adapted from a bacterial immune system, and involves targeting of the Cas9 nuclease to sites of interest via guide RNAs (Gasiunas et al. 2012; Jinek et al. 2012). What happens next is highly dependent on how the break is repaired by the cell, which can vary depending on factors such as the cell type/state and availability of a repair template (reviewed in Ceccaldi et al. 2016).

Precise changes can be introduced into the genome using CRISPR/Cas9 if a homologous DNA repair template is supplied at the same time, permitting repair by the highfidelity homology-directed repair (HDR) pathway (Cong et al. 2013; Paquet et al. 2016). Unfortunately, the therapeutic potential of HDR-based approaches for in vivo genome editing approaches is limited by their inefficiency in human cells (Mao et al. 2008). Instead, the predominant repair pathway for DSBs in mammalian cells, including post-mitotic neurons, is non-homologous end-joining (NHEJ), which generates a heterogeneous range of repair products (Rothkamm et al. 2003; Ren and Peña De Ortiz, 2002; reviewed in Chang et al. 2017). It was previously thought that repair outcomes were random and were therefore of limited therapeutic use beyond gene disruption. However, recently it has been shown that consequences for a given target site are highly reproducible and can often be accurately predicted (van Overbeek et al. 2016; Allen et al. 2018; Shen et al. 2018; Chakrabarti et al. 2019). The potential of predictable template-free CRISPR/Cas9 editing has been demonstrated for pathogenic frameshift mutations, for example, by identifying targets which predominantly restore the wild-type reading frame (Shen et al. 2018). Other possibilities for therapeutic genome editing using programmable nucleases are discussed in Wang et al. (2020).

\section{Direct base-editing}

This highly desirable option seemed technically beyond reach until a recent breakthrough came with the development of programmable DNA base editors, which can change base pairs without requiring DSBs, homology-directed repair or donor DNA templates (Komor et al. 2016; Gaudelli et al. 2017). Base editors typically consist of a catalytically impaired Cas9 fused to cytidine-or adenosine-deaminase enzymes (reviewed in Porto et al. 2020). These artificial proteins can be targeted to disease-causing mutations and potentially revert them to the wild-type sequence, offering permanent correction in a single-dose. "Prime editing" is another exciting development, which involves catalytically impaired Cas9 fused to an engineered reverse transcriptase, and has the potential to correct a broad range of mutations (Anzalone et al. 2019).

\section{RNA editing}

Instead of editing the DNA, an alternative strategy is to correct its messenger RNA (mRNA) transcripts. Programmable RNA editors have been developed which fuse domains from endogenous RNA editing enzymes, for example the deaminase domain of RNA-specific adenosine deaminases, to the RNA binding domain from a different protein (Montiel-Gonzalez et al. 2013; Cox et al. 2017). Engineered guide RNAs 
are then introduced to recruit the RNA editor to its target sequence in the mutant mRNA. In the case of RTT, this approach has the theoretical potential to correct at least $36 \%$ of disease-causing mutations by adenosine-to-inosine editing (Sinnamon et al. 2020). Introduction of RNA editors into the hippocampus of Mecp2-mutant mice corrected $~ 50 \%$ of mRNA transcripts and restored MeCP2 function to a similar level (Sinnamon et al. 2020). This is likely to be enough for significant phenotypic improvement in mouse disease models, although this is yet to be experimentally tested.

\section{The challenge of delivery}

As mentioned above, AAV-mediated delivery of components leads to widespread expression of protein throughout the brain (Foust et al. 2009; Chan et al. 2017). An important benefit is that expression of the cargo gene is sustained for months or years in non-dividing cells. Transgene expression has been reported to persist in neurons for more than 4 years in humans (Mittermeyer et al. 2011) and at least 15 years in non-human primates (Sehara et al. 2017). This is a critical advantage for gene transfer strategies because it allows them to provide long-term correction without the need for re-administration.

\section{Issues with gene dosage}

Despite the attractions of AAV vectors, they have limitations. An important reservation is lack of control over the number of virus particles delivered per cell. This is of particular concern where the level of the therapeutic agent needs to be tightly regulated. For example, while insufficient MeCP2 leads to RTT, too much MeCP2 is associated with the severe neurological disorder "MeCP2 duplication syndrome" (Collins et al. 2004; Luikenhuis et al. 2004; Van Esch et al. 2005). Accordingly, toxicity due to MeCP2 overexpression has been observed in preclinical gene transfer studies in wild-type animals (Gadalla et al. 2017; Sinnett et al. 2017). Furthermore, in female RTT patients half of the cells express normal levels of $\mathrm{MeCP} 2$, which means that indiscriminate delivery of AAV vectors to these cells may lead to overexpression-mediated toxicity. Another example of a dosage-sensitive gene is $U B E 3 A$, whose mutation can cause either Angelman syndrome or non-syndromic autism as a result of loss-of-function or overexpression, respectively (reviewed in Khatri and Man 2019). To counter this problem, the search is on for regulatory elements that could be included within the delivery vector, although packaging constraints mean that it is often difficult to fit all necessary nucleic acid sequences within a single virus.

An important advantage of Cas9 nucleases and DNA/ RNA editors is that they avoid deleterious over-expression of this kind since the gene remains under the control of its natural regulatory elements. Here again, however, the large size of these genome editing proteins makes AAV-mediated delivery a challenge. Solutions to this problem include use of smaller variants of Cas 9 or splitting the transgene into two segments which automatically fuse together upon expression in the cell (reviewed in Wang et al. 2020). Encouragingly, direct injection of dual AAV vectors expressing two halves of a split base editor achieved base editing efficiencies of up to $59 \%$ in the mouse cortex (Levy et al. 2020).

\section{Transduction efficiency}

For genetic diseases affecting the brain, the low level of neuronal infection by available AAV serotypes is also a critically important issue. Although increasing the dose of AAV9 vectors enhances brain transduction, this can lead to a concomitant increase in transduction of peripheral tissues, such as the liver and heart (Gadalla et al. 2013, 2017). Importantly, high doses of AAV vectors should be avoided, as this can lead to severe toxicity, including death, in both non-human primates (Hinderer et al. 2018; Hordeaux et al. 2018) and humans (Wilson and Flotte, 2020). While engineered AAV variants can infect the majority of neurons in specific strains of mice (Deverman et al. 2016; Chan et al. 2017; Hordeaux et al. 2018; Huang et al. 2019), serotypes that can achieve similar levels in non-human primates have not yet been reported. Consequently, therapies that depend on the delivery of DNA to most neurons throughout the brain await improvements in vector infectivity.

In spite of the relatively low efficiency of AAV transduction, it remains possible that transduction of a small proportion of neurons may nevertheless yield significant therapeutic benefit. In the case of RTT, for example, reversal experiments and gene therapy studies in Mecp2-null mice have given encouraging results. Activation of Mecp 2 expression in 70 to $80 \%$ of cells in the brain led to an impressive reversal of most RTT-like symptoms in Mecp2-null mice (Guy et al. 2007; Robinson et al. 2012), but also transduction of $10-40 \%$ of cells by direct brain injection with AAV$M E C P 2$ vectors improved RTT-like symptoms and greatly extended survival (Gadalla et al. 2017). Even transduction efficiencies as low as 3-5\% significantly improved survival of adult Mecp2-null mice (Gadalla et al. 2017). These results suggest that desirable symptomatic improvements may result even if only a small proportion of brain cells have MeCP2 expression restored.

\section{Immunogenicity}

Another challenge is the potential for foreign transgenes (e.g. bacterially derived Cas9), to stimulate host immune responses. Long-term expression of CRISPR/Cas9 
components was generally well tolerated in a mouse model of muscular dystrophy after one year, although a host immune response was detected in nearly all mice injected as adults (Nelson et al. 2019). The prevalence of pre-existing immunity to AAV capsids (Calcedo et al. 2009; Kay, 2011; Mingozzi and High, 2013) and Cas9 nucleases (Charlesworth et al. 2019; Wagner et al. 2019) in humans is another concern. Current engineered capsid variants may not be different enough from naturally occurring AAV serotypes to evade detection by neutralising antibodies, although efforts are underway to develop highly diverse variants to counter this problem (Bryant et al. 2021). Direct administration to the immune-privileged brain could potentially mitigate these problems, as might immunosuppressive strategies (reviewed in Perez et al. 2020).

\section{Genotoxicity}

Off-target editing is one of the primary safety concerns for the use of genome editors (nuclease-based or DNA base editors), since undesirable changes could be permanently introduced into the genome (reviewed in Doudna 2020). While sustained expression of AAV vectors is an advantage for gene transfer strategies, prolonged expression of CRISPR/ Cas9 components may be detrimental as it increases the likelihood of off-target editing (Zuris et al. 2014; Ishida et al. 2015). This effect may be mitigated by engineering high-fidelity variants and/or minimising the duration of Cas9 expression (reviewed in Zhuo et al. 2021). Alternatively, non-viral delivery vehicles, such as nanoparticles, could be used. Non-viral delivery of CRISPR/Cas9 components can mediate localised genome editing in the brain close to the administration site (Staahl et al. 2017; Lee et al. 2018), but a drawback is that they are unable at present to provide widespread expression throughout the brain.

An additional concern for AAV-mediated delivery of programmable nucleases is accumulating evidence that the introduction of DSBs into the genome during editing can lead to integration of the AAV vector into the host genome (Miller et al. 2003, 2004; Anguela et al. 2013; Hanlon et al. 2019; Nelson et al. 2019). This problem is largely avoided by the use of base editors, which do not tend to generate DSBs in the DNA (reviewed in Anzalone et al. 2020). This represents a further advantage of the base editing approach.

\section{Efficacy and cost}

A critical question for all genetic therapies concerns efficacy. Will the intervention reverse or significantly ameliorate symptoms on a long-term basis without causing undesirable side effects? Even if animal experiments lead us to the strong conclusion that the answer to this question is 'yes', the leap to humans is inevitably accompanied by risk. Due to this uncertainty, arguments for or against genetic therapies ebb and flow. An example is the proposal that development of a "cure" for severe neurological disorders may in fact be undesirable from several perspectives (Clarke and Abdala Sheikh 2018). For example, in the context of RTT it was noted that rapid activation of Mecp 2 expression in mice resulted in toxicity and lethality within a few days (Guy et al. 2007). Sudden re-expression of MeCP2 in humans, it was suggested, may lead to autonomic instability (Clarke and Abdala Sheikh 2018). However, due to the low transduction efficiency of current delivery vectors, it is unlikely that MECP2 will be corrected in a sufficient number of neurons to cause toxicity. Other highlighted uncertainties persist, however, including the impact of changes in brain volume and the psychological adjustments that would accompany improvements in brain function. For this and other genetic disorders of the brain, detailed pre-clinical research has the potential to minimise the chances of an adverse response, but only application of the therapeutic technology in the clinic can fully assess outcomes. In the case of RTT, preclinical studies have confirmed that gene transfer is a promising therapeutic strategy for RTT. Accordingly, several candidates are currently under development in academic programmes and commercially, aiming towards clinical trials within the next few years.

A serious caveat to genetic therapies is their high cost. For example, Zolgensma for the treatment of spinal muscular atrophy has been dubbed the "most expensive drug in the world" costing more than $\$ 2$ million in the US. This means that in countries without national healthcare programmes, these therapeutics are only available to the privileged. The cost of treatment has been defended by claims that it should be measured against the lifetime of healthcare treatment that should no longer be needed (or at least not to the same extent). Based on precedent, it seems likely that costs will decrease as treatments of this kind become more routine, but given the rarity of some such disorders, bespoke treatments seem destined to always be expensive. Social justice requires that novel therapies that turn out to be effective should be available to all, regardless of socio-economic status. Accordingly, the World Health Organisation (WHO 2021) has recognised the importance of establishing global guidelines to help ensure equitable access to genome editing technologies. However, this will remain a challenging issue and it is likely that different payment strategies will be required, as well as international partnerships to ensure access in low- and middle-income countries. Scientists can also play a role here, as illustrated by the insistence by the Oxford group that the AstraZeneca SARS-CoV-2 vaccine was distributed on a not-for-profit basis. 


\section{Ethical concerns}

Editing in germline cells raises long-standing ethical challenges and is currently illegal, so genome editing must be confined to somatic cells. Fortunately, this is technically straightforward, as any modifications introduced into the brain genome will only affect the treated individual and cannot be passed to future generations. Needless to say, rigorous testing will be required to address safety issues and minimise the possibility of unexpected consequences (Nuffield Council on Bioethics 2016; National Academy of Sciences 2020). The need for statutory guidelines has been highlighted by a controversial study which claimed to edit the CCR5 gene in human embryos, before subsequently implanting edited embryos into two women (commented on in Cyranoski 2019). The aim of the procedure was to disable the CCR5 gene in order to protect the recipients from certain strains of HIV infection, but the potential for unwanted consequences, including off-target edits or increased susceptibility to other diseases, such as West Nile Virus, were inadequately investigated, making this a high-risk intervention. In light of this scandal, a WHO advisory committee was developed to establish international guidelines for human genome editing. It will be critical that individual scientists, and the scientific community as a whole, adhere to guidelines and ethical regulations set by regulatory bodies, to protect patients, as well as scientific progress.

\section{Concluding remarks}

We are in the midst of a technological revolution which brings closer the possibility of correcting genetic diseases. If the technology brings the promised benefits and alleviates suffering, ethical opposition to manipulation of genes may wane. As with all new medical procedures, however, these advances cannot be achieved without risk. Willingness to undertake this risk is dependent on the severity of the relevant disorder, but also on the attitudes of those concerned, including parents/carers and society at large. Unfortunately, as in the case of organ transplants and many other aspects of medicine in times past, the first usage in humans is fraught with uncertainty. This has been highlighted by the recent fatalities in the Audentes Therapeutics' AAV gene therapy trial (AT132) for the treatment of X-linked myotubular myopathy (Harrison 2020). It is imperative that there is full transparency within the scientific community, particularly with regard to reporting adverse effects, to ensure that treatments are both safe and effective. However, it is worth noting that the risks of no treatment are also very high for severe neurological disorders and, if successful, patients (and their families) will reap the rewards of a life-changing therapy for these highly debilitating disorders. While a risk-averse (and litigious) society may hesitate at the prospect of the unknown, new therapeutic horizons will never be explored by stasis.

Funding A.B. is supported by a Wellcome Centre Grant (091580/Z/10/Z), a Wellcome Investigator Award (107930/Z/15/Z), a European Research Council Advanced grant (EC 694295 Gen-Epix) and is a member of the Simons Initiative for the Developing Brain. L.F. is supported by a Wellcome 4 year PhD studentship (109090).

Availability of data and material Not applicable.

Code availability Not applicable.

\section{Declarations}

Conflict of interest On behalf of all authors, the corresponding author states that there is no conflict of interest.

Open Access This article is licensed under a Creative Commons Attribution 4.0 International License, which permits use, sharing, adaptation, distribution and reproduction in any medium or format, as long as you give appropriate credit to the original author(s) and the source, provide a link to the Creative Commons licence, and indicate if changes were made. The images or other third party material in this article are included in the article's Creative Commons licence, unless indicated otherwise in a credit line to the material. If material is not included in the article's Creative Commons licence and your intended use is not permitted by statutory regulation or exceeds the permitted use, you will need to obtain permission directly from the copyright holder. To view a copy of this licence, visit http://creativecommons.org/licenses/by/4.0/.

\section{References}

Allen F, Crepaldi L, Alsinet C, Strong AJ, Kleshchevnikov V, De Angeli P, Páleníková P, Khodak A, Kiselev V, Kosicki M, Bassett AR, Harding H, Galanty Y, Muñoz-martínez F, Metzakopian E, Jackson SP, Parts L (2018) Predicting the mutations generated by repair of Cas9-induced double-strand breaks. Nat Biotechnol 37:64-72

Amir RE, Van den Veyver IB, Wan M, Tran CQ, Francke U, Zoghbi HY (1999) Rett syndrome is caused by mutations in X-linked MECP2, encoding methyl-CpG-binding protein 2. Nat Genet 23: $185-188$

Anguela XM, Sharma R, Doyon Y, Miller JC, Li H, Haurigot V, Rohde ME, Wong SY, Davidson RJ, Zhou S, Gregory PD, Holmes MC, High KA (2013) Robust ZFN-mediated genome editing in adult hemophilic mice. Blood 122:3283-3287

Anzalone AV, Randolph PB, Davis JR, Sousa AA, Koblan LW, Levy JM, Chen PJ, Wilson C, Newby GA, Raguram A, Liu DR (2019) Search-and-replace genome editing without double-strand breaks or donor DNA. Nature 576:149-157

Anzalone AV, Koblan LW, Liu DR (2020) Genome editing with CRISPR-Cas nucleases, base editors, transposases and prime editors. Nat Biotechnol 38:824-844 
Bryant DH, Bashir A, Sinai S, Jain NK, Ogden PJ, Riley PF, Church GM, Colwell LJ, Kelsic ED (2021) Deep diversification of an AAV capsid protein by machine learning. Nat Biotechnol 39:691-696

Calcedo R, Vandenberghe LH, Gao G, Lin J, Wilson JM (2009) Worldwide epidemiology of neutralizing antibodies to adeno-associated viruses. J Infect Dis 199:381-390

Ceccaldi R, Rondinelli B, D'Andrea AD (2016) Repair pathway choices and consequences at the double-strand break. Trends Cell Biol 26:52-64

Chakrabarti AM, Henser-Brownhill T, Monserrat J, Poetsch AR, Luscombe NM, Scaffidi P (2019) Target-specific precision of CRISPR-mediated genome editing. Mol Cell 73:699-713.e6

Chan KY, Jang MJ, Yoo BB, Greenbaum A, Ravi N, Wu WL, Sánchez-Guardado L, Lois C, Mazmanian SK, Deverman BE, Gradinaru V (2017) Engineered AAVs for efficient noninvasive gene delivery to the central and peripheral nervous systems. Nat Neurosci 20:1172-1179

Chang HHY, Pannunzio NR, Adachi N, Lieber MR (2017) Nonhomologous DNA end joining and alternative pathways to double-strand break repair. Nat Rev Mol Cell Biol 18:495-506

Charlesworth CT, Deshpande PS, Dever DP, Camarena J, Lemgart VT, Cromer MK, Vakulskas CA, Collingwood MA, Zhang L, Bode NM, Behlke MA, Dejene B, Cieniewicz B, Romano R, Lesch BJ, Gomez-Ospina N, Mantri S, Pavel-Dinu M, Weinberg KI, Porteus MH (2019) Identification of preexisting adaptive immunity to Cas9 proteins in humans. Nat Med 25:249-254

Chen RZ, Akbarian S, Tudor M, Jaenisch R (2001) Deficiency of methyl-CpG binding protein-2 in CNS neurons results in a Rettlike phenotype in mice. Nat Genet 27:327-331

Clarke AJ, Abdala Sheikh AP (2018) A perspective on 'cure' for Rett syndrome. Orphanet J Rare Dis 13:1-5

Collins AL, Levenson JM, Vilaythong AP, Richman R, Armstrong DL, Noebels JL, Sweatt JD, Zoghbi HY (2004) Mild overexpression of $\mathrm{MeCP} 2$ causes a progressive neurological disorder in mice. Hum Mol Genet 13:2679-2689

Cong L, Ran FA, Cox D, Lin S, Barretto R, Habib N, Hsu PD, Wu X, Jiang W, Marraffini LA, Zhang F (2013) Multiplex Genome Engineering Using CRISPR/Cas Systems. Science (80-) 339:819-823

Cox DBT, Platt RJ, Zhang F (2015) Therapeutic genome editing: prospects and challenges. Nat Med 21:121-131

Cox DBT, Gootenberg JS, Abudayyeh OO, Franklin B, Kellner MJ, Joung J, Zhang F (2017) RNA editing with CRISPR-Cas13. Science (80-) 358:1019-1027

Cyranoski D (2019) The CRISPR-baby scandal: what's next for human gene-editing. Nature 566:440-442

Deverman BE, Pravdo PL, Simpson BP, Kumar SR, Chan KY, Banerjee A, Wu WL, Yang B, Huber N, Pasca SP, Gradinaru V (2016) Cre-dependent selection yields AAV variants for widespread gene transfer to the adult brain. Nat Biotechnol 34:204-209

Doudna JA (2020) The promise and challenge of therapeutic genome editing. Nature 578:229-236

Fitzgerald TW, Gerety SS, Jones WD, Van Kogelenberg M, King DA, McRae J, Morley KI, Parthiban V, Al-Turki S, Ambridge K, Barrett DM, Bayzetinova T, Clayton S, Coomber EL, Gribble S, Jones P, Krishnappa N, Mason LE, Middleton A, Miller $R$ et al (2015) Large-scale discovery of novel genetic causes of developmental disorders. Nature 519:223-228

Foust KD, Nurre E, Montgomery CL, Hernandez A, Chan CM, Kaspar BK (2009) Intravascular AAV9 preferentially targets neonatal neurons and adult astrocytes. Nat Biotechnol 27:59-65

Friedmann T, Roblin R (1972) Gene therapy for human genetic disease? Science (80-) 175:949-955

Gadalla KKE, Bailey MES, Spike RC, Ross PD, Woodard KT, Kalburgi SN, Bachaboina L, Deng JV, West AE, Samulski RJ,
Gray SJ, Cobb SR (2013) Improved survival and reduced phenotypic severity following AAV9/MECP2 gene transfer to neonatal and juvenile male Mecp2 knockout mice. Mol Ther 21:18-30

Gadalla KKE, Vudhironarit T, Hector RD, Sinnett S, Bahey NG, Bailey MES, Gray SJ, Cobb SR (2017) Development of a novel AAV gene therapy cassette with improved safety features and efficacy in a mouse model of Rett syndrome. Mol Ther Methods Clin Dev 5:180-190

Gasiunas G, Barrangou R, Horvath P, Siksnys V (2012) Cas9-crRNA ribonucleoprotein complex mediates specific DNA cleavage for adaptive immunity in bacteria. Proc Natl Acad Sci USA 109:2579-2586

Gaudelli NM, Komor AC, Rees HA, Packer MS, Badran AH, Bryson DI, Liu DR (2017) Programmable base editing of A $\bullet T$ to G•C in genomic DNA without DNA cleavage. Nature 551:464-471

Ginn SL, Amaya AK, Alexander IE, Edelstein M, Abedi MR (2018) Gene therapy clinical trials worldwide to 2017: an update. J Gene Med 20:1-16

Guy J, Hendrich B, Holmes M, Martin JE, Bird A (2001) A mouse Mecp2-null mutation causes neurological symptoms that mimic Rett syndrome. Nat Genet 27:322-326

Guy J, Gan J, Selfridge J, Cobb S, Bird A (2007) Reversal of neurological defects in a mouse model of Rett syndrome. Science (80-) 315:1143-1147

Hanlon KS, Kleinstiver BP, Garcia SP, Zaborowski MP, Volak A, Spirig SE, Muller A, Sousa AA, Tsai SQ, Bengtsson NE, Lööv C, Ingelsson M, Chamberlain JS, Corey DP, Aryee MJ, Joung JK, Breakefield XO, Maguire CA, György B (2019) High levels of AAV vector integration into CRISPR-induced DNA breaks. Nat Commun 10:4439

Harrison C (2020) High-dose AAV gene therapy deaths. Nat Biotechnol 38:910-910

Hinderer C, Katz N, Buza EL, Dyer C, Goode T, Bell P, Richman LK, Wilson JM (2018) Severe toxicity in nonhuman primates and piglets following high-dose intravenous administration of an adeno-associated virus vector expressing human SMN. Hum Gene Ther 29:285-298

Hordeaux J, Wang Q, Katz N, Buza EL, Bell P, Wilson JM (2018) The neurotropic properties of AAV-PHP.B are limited to C57BL/6J mice. Mol Ther 26:664-668

Huang Q, Chan KY, Tobey IG, Chan YA, Poterba T, Boutros CL, Balazs AB, Daneman R, Bloom JM, Seed C, Deverman BE (2019) Delivering genes across the blood-brain barrier: LY6A, a novel cellular receptor for AAV-PHP.B capsids. PLoS ONE 14:1-17

Hudry E, Vandenberghe LH (2019) Therapeutic AAV gene transfer to the nervous system: a clinical reality. Neuron 101:839-862

Ishida K, Gee P, Hotta A (2015) Minimizing off-target mutagenesis risks caused by programmable nucleases. Int J Mol Sci 16:24751-24771

Jinek M, Chylinski K, Fonfara I, Hauer M, Doudna JA, Charpentier E (2012) A programmable dual-RNA-guided DNA endonuclease in adaptive bacterial immunity. Science 337:816-821

Kay MA (2011) State-of-the-art gene-based therapies: the road ahead. Nat Rev Genet 12:316-328

Khatri N, Man HY (2019) The autism and Angelman syndrome protein Ube3A/E6AP: The gene, E3 ligase ubiquitination targets and neurobiological functions. Front Mol Neurosci 12:1-12

Komor AC, Kim YB, Packer MS, Zuris JA, Liu DR (2016) Programmable editing of a target base in genomic DNA without doublestranded DNA cleavage. Nature 533:420-424

Lee B, Lee K, Panda S, Gonzales-Rojas R, Chong A, Bugay V, Park HM, Brenner R, Murthy N, Lee HY (2018) Nanoparticle delivery of CRISPR into the brain rescues a mouse model of fragile $\mathrm{X}$ syndrome from exaggerated repetitive behaviours. Nat Biomed Eng 2:497-507 
Levy JM, Yeh WH, Pendse N, Davis JR, Hennessey E, Butcher R, Koblan LW, Comander J, Liu Q, Liu DR (2020) Cytosine and adenine base editing of the brain, liver, retina, heart and skeletal muscle of mice via adeno-associated viruses. Nat Biomed Eng 4:97-110

Luikenhuis S, Giacometti E, Beard CF, Jaenisch R (2004) Expression of MeCP2 in postmitotic neurons rescues Rett syndrome in mice. Proc Natl Acad Sci USA 101:6033-6038

Mao Z, Bozzella M, Seluanov A, Gorbunova V (2008) Comparison of nonhomologous end joining and homologous recombination in human cells. DNA Repair (amst) 7:1765-1771

McRae JF, Clayton S, Fitzgerald TW, Kaplanis J, Prigmore E, Rajan D, Sifrim A, Aitken S, Akawi N, Alvi M, Ambridge K, Barrett DM, Bayzetinova T, Jones P, Jones WD, King D, Krishnappa N, Mason LE, Singh T, Tivey AR et al (2017) Prevalence and architecture of de novo mutations in developmental disorders. Nature 542:433-438

Mendell JR, Al-Zaidy S, Shell R, Arnold WD, Rodino-Klapac LR, Prior TW, Lowes L, Alfano L, Berry K, Church K, Kissel JT, Nagendran S, L'Italien J, Sproule DM, Wells C, Cardenas JA, Heitzer MD, Kaspar A, Corcoran S, Braun L et al (2017) Singledose gene-replacement therapy for spinal muscular atrophy. N Engl J Med 377:1713-1722

Miller DG, Petek LM, Russell DW (2003) Human gene targeting by adeno-associated virus vectors is enhanced by DNA double-strand breaks. Mol Cell Biol 23:3550-3557

Miller DG, Petek LM, Russell DW (2004) Adeno-associated virus vectors integrate at chromosome breakage sites. Nat Genet 36:767-773

Mingozzi F, High KA (2013) Immune responses to AAV vectors: overcoming barriers to successful gene therapy. Blood 122:23-36

Mittermeyer G, Christine CW, Rosenbluth KH, Baker SL, Starr P, Larson P, Kaplan PL, Forsayeth J, Aminoff MJ, Bankiewicz KS (2011) Long-term evaluation of a phase 1 study of AADC gene therapy for Parkinson's disease. Hum Gene Ther 23:377-381

Montiel-Gonzalez MF, Vallecillo-Viejo I, Yudowski GA, Rosenthal JJC (2013) Correction of mutations within the cystic fibrosis transmembrane conductance regulator by site-directed RNA editing. Proc Natl Acad Sci USA 110:18285-18290

National Academy of Sciences (2020) Heritable human genome editing. National Academies Press, Washington D.C.

Nelson CE, Wu Y, Gemberling MP, Oliver ML, Waller MA, Bohning JD, Robinson-Hamm JN, Bulaklak K, Castellanos Rivera RM, Collier JH, Asokan A, Gersbach CA (2019) Long-term evaluation of AAV-CRISPR genome editing for Duchenne muscular dystrophy. Nat Med 25:427-432

Nuffield Council on Bioethics (2016) Genome editing and human reproduction: social and ethical issues

Paquet D, Kwart D, Chen A, Sproul A, Jacob S, Teo S, Olsen KM, Gregg A, Noggle S, Tessier-Lavigne M (2016) Efficient introduction of specific homozygous and heterozygous mutations using CRISPR/Cas9. Nature 533:125-129

Perez BA, Shutterly A, Chan YK, Byrne BJ, Corti M (2020) Management of neuroinflammatory responses to AAV-mediated gene therapies for neurodegenerative diseases. Brain Sci 10:119

Porto EM, Komor AC, Slaymaker IM, Yeo GW (2020) Base editing: advances and therapeutic opportunities. Nat Rev Drug Discov 19:839-859

Ren K, Peña De Ortiz S (2002) Non-homologous DNA end joining in the mature rat brain. J Neurochem 80:949-959

Robinson L, Guy J, McKay L, Brockett E, Spike RC, Selfridge J, De Sousa D, Merusi C, Riedel G, Bird A, Cobb SR (2012) Morphological and functional reversal of phenotypes in a mouse model of Rett syndrome. Brain 135:2699-2710

Rothkamm K, Krüger I, Thompson LH, Kru I, Lo M (2003) Pathways of DNA double-strand break repair during the mammalian cell cycle pathways of DNA double-strand break repair during the mammalian cell cycle. Mol Cell Biol 23:5706-5715

Sehara Y, Fujimoto KI, Ikeguchi K, Katakai Y, Ono F, Takino N, Ito M, Ozawa K, Muramatsu SI (2017) Persistent expression of dopamine-synthesizing enzymes 15 years after gene transfer in a primate model of Parkinson's disease. Hum Gene Ther Clin Dev 28:74-79

Shen MW, Arbab M, Hsu JY, Worstell D, Culbertson SJ, Krabbe O, Cassa CA, Liu DR, Gifford DK, Sherwood RI (2018) Predictable and precise template-free CRISPR editing of pathogenic variants. Nature 563:646-651

Silva-Santos S, Van Woerden GM, Bruinsma CF, Mientjes E, Jolfaei MA, Distel B, Kushner SA, Elgersma Y (2015) Ube3a reinstatement identifies distinct developmental windows in a murine Angelman syndrome model. J Clin Invest 125:2069-2076

Sinnamon JR, Kim SY, Fisk JR, Song Z, Nakai H, Jeng S, McWeeney SK, Mandel G (2020) In vivo repair of a protein underlying a neurological disorder by programmable RNA editing. Cell Rep 32:107878

Sinnett SE, Hector RD, Gadalla KKE, Heindel C, Chen D, Zaric V, Bailey MES, Cobb SR, Gray SJ (2017) Improved MECP2 gene therapy extends the survival of MeCP2-null mice without apparent toxicity after intracisternal delivery. Mol Ther Methods Clin Dev 5:106-115

Staahl BT, Benekareddy M, Coulon-Bainier C, Banfal AA, Floor SN Sabo JK, Urnes C, Munares GA, Ghosh A, Doudna JA (2017) Efficient genome editing in the mouse brain by local delivery of engineered Cas9 ribonucleoprotein complexes. Nat Biotechnol 35:431-434

Van Esch H, Bauters M, Ignatius J, Jansen M, Raynaud M, Hollanders K, Lugtenberg D, Bienvenu T, Jensen LR, Gecz J, Moraine C, Marynen P, Fryns J-P, Froyen G (2005) Duplication of the $\mathrm{MECP} 2$ region is a frequent cause of severe mental retardation and progressive neurological symptoms in males. Am J Hum Genet 77:442-453

van Overbeek M, Capurso D, Carter MM, Thompson MS, Frias E, Russ C, Reece-Hoyes JS, Nye C, Gradia S, Vidal B, Zheng J, Hoffman GR, Fuller CK, May AP (2016) DNA repair profiling reveals nonrandom outcomes at Cas9-mediated breaks. Mol Cell 63:633-646

Wagner DL, Amini L, Wendering DJ, Burkhardt LM, Akyüz L, Reinke P, Volk HD, Schmueck-Henneresse M (2019) High prevalence of Streptococcus pyogenes Cas9-reactive T cells within the adult human population. Nat Med 25:242-248

Wang D, Zhang F, Gao G (2020) CRISPR-based therapeutic genome editing: strategies and in vivo delivery by AAV vectors. Cell 181:136-150

WHO (2021) WHO Expert Advisory Committee on Developing Global Standards for Governance and Oversight of Human Genome Editing. Human Genome Editing: recommendations

Wilson JM, Flotte TR (2020) Moving forward after two deaths in a gene therapy trial of myotubular myopathy. Hum Gene Ther 31:695-696

Zhuo C, Zhang J, Lee JH, Jiao J, Cheng D, Liu L, Kim HW, Tao Y, Li M (2021) Spatiotemporal control of CRISPR/Cas9 gene editing. Signal Transduct Target Ther 6:1-18

Zuris JA, Thompson DB, Shu Y, Guilinger JP, Bessen JL, Hu JH, Maeder ML, Joung JK, Chen Z-Y, Liu DR (2014) Cationic lipidmediated delivery of proteins enables efficient protein-based genome editing in vitro and in vivo. Nat Biotechnol 33:73-80

Publisher's Note Springer Nature remains neutral with regard to jurisdictional claims in published maps and institutional affiliations. 